\title{
Micro to nanostructural observations in neutron irradiated nuclear graphites PCEA and PCIB
}

\author{
H.M. Freeman ${ }^{\text {a, b, }{ }^{*} \text {, B.E. Mironov }}{ }^{\text {b, }{ }^{* *}, \text { W. Windes }}{ }^{\text {c, }}{ }^{d}$, M.M. Alnairi ${ }^{b}$, A.J. Scott ${ }^{b}$, \\ A.V.K. Westwood ${ }^{\text {b }}$, R.M.D. Brydson ${ }^{\mathrm{b}}$

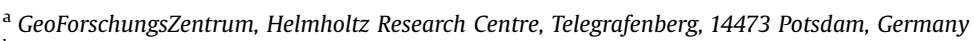 \\ ${ }^{\mathrm{b}}$ School of Chemical and Process Engineering, University of Leeds, Leeds LS2 9JT, UK \\ ${ }^{c}$ Idaho National Laboratory, 2351 N. Boulevard, Idaho Falls, ID 83415, USA \\ ${ }^{\mathrm{d}}$ Center for Advanced Energy Studies, 995 University Blvd, Idaho Falls, ID 83415, USA
}

\section{A R T I C L E I N F O}

\section{Article history:}

Received 13 January 2017

Received in revised form

21 April 2017

Accepted 12 May 2017

Available online 12 May 2017

\begin{abstract}
A B S T R A C T
The neutron irradiation-induced structural changes in nuclear grade graphites PCEA and PCIB were investigated using scanning electron microscopy (SEM), X-ray diffraction (XRD), Raman spectroscopy, transmission electron microscopy (TEM), selected area electron diffraction (SAED) and electron energy loss spectroscopy (EELS). The graphite samples were irradiated at the Advanced Test Reactor at the Idaho National Laboratory. Received doses ranged from 1.5 to 6.8 displacements per atom and irradiation temperatures varied between $350{ }^{\circ} \mathrm{C}$ and $670{ }^{\circ} \mathrm{C}$.

XRD and Raman measurements provided evidence for irradiation induced crystallite fragmentation, with crystallite sizes reduced by $39-55 \%$. Analysis of TEM images was used to quantify fringe length, tortuosity, and relative misorientation of planes, and indicated that neutron irradiation induced basal plane fragmentation and curvature. EELS was used to quantify the proportion of $\mathrm{sp}^{2}$ bonding and specimen density; a slight reduction in planar- $\mathrm{sp}^{2}$ content (due to the buckling basal planes and the introduction of non-six-membered rings) agreed with the observations from TEM.
\end{abstract}

๑ 2017 The Authors. Published by Elsevier B.V. This is an open access article under the CC BY license (http://creativecommons.org/licenses/by/4.0/).

\section{Introduction}

Graphite is a key component in some designs of current (e.g. advanced gas cooled) and future (e.g. high temperature gas-cooled) civil nuclear reactors whose lifetimes are heavily dependent on the physical and chemical performance of the graphite. Although its primary role is to moderate the energies of neutrons in the fission process, the graphite core also provides structural support, accommodates the fuel and control rods, and allows for coolant flow. Exposure to neutron radiation at temperatures over ca. $350{ }^{\circ} \mathrm{C}$ induces complex structural changes over many length scales. The lifetime of such reactors is therefore primarily limited by the performance of the irreplaceable graphite within the working reactor core, so an accurate measure of its condition is essential for reactor

\footnotetext{
* Corresponding author. Helmholtz Research Centre, GeoForschungsZentrum, Telegrafenberg, 14473 Potsdam, Germany.

** Corresponding author.

E-mail addresses: freeman@gfz-potsdam.de (H.M. Freeman), bemironov@gmail. com (B.E. Mironov).
}

safety.

Nuclear graphite is a synthetic material produced from pitch and petroleum coke particles, with a high degree of crystallinity following thermal treatment at high temperatures over a number of stages [1]. The resultant product contains a majority of filler particles, a minority of binder phase, and also voids/pores. Both the filler and binder phases have potentially inter- and intra-structural porosity ranging from Mrozowski cracks in and between crystallites to micro- and macro-pores around domains and particles [2,3].

Monitoring the changes in bulk microstructural properties such as porosity and crack volume with irradiation is important as several physical and chemical property changes occur. The most significant effects are seen in the Young's modulus and thermal conductivity; both reduce by more than half for a $30 \%$ porous graphite as compared to a completely non-porous control specimen [4,5]. Scanning electron microscopy (SEM) can be used to measure the shape and size of filler and binder phases and the size, shape and distribution of the larger pores; particle sizes have been found to vary from ca. $20 \mu \mathrm{m}-1.6 \mathrm{~mm}$. Porosity can occupy up to $25 \%$ of the volume of the material and vary in size, from Angstroms 
to millimeters. Narrow lenticular (Mrozowski) cracks parallel to the c-axis are usually found in the filler phase and near-spherical pores are usually found in the binder phase [3,6-8].

In addition to SEM, the two common microstructural techniques which can probe crystallinity are X-ray diffraction (XRD) and Raman spectroscopy. Irradiation studies of highly oriented pyrolytic graphite (HOPG) at Oak Ridge National Laboratory showed a significant reduction in crystallite size with increasing dose [9]. Neutron irradiation was conducted at ca. $600{ }^{\circ} \mathrm{C}$, to doses between 1.5 and 7 displacements per atom (dpa). Analysis of the (110) and (002) XRD peaks provided coherence lengths La and Lc respectively. It was shown that large crystallites, of dimension $55 \mathrm{~nm}$ $\left(L_{a}\right) \times 70 \mathrm{~nm}\left(L_{c}\right)$, were found in virgin HOPG. After 3-7 dpa of neutron irradiation, crystallite fragmentation resulted in a $60 \%\left(\mathrm{~L}_{\mathrm{a}}\right)$ and $70 \%\left(\mathrm{~L}_{\mathrm{c}}\right)$ reduction in coherence lengths. XRD was also used by Zhou et al. to characterize virgin nuclear grade graphites PGA, PCEA, IG110 and RID, however in this study the (100) peak was used to calculate the coherence length $\mathrm{L}_{\mathrm{a}}[10]$. Kwiecinska et al. performed Raman spectroscopy on a range of carbonaceous materials of varying order and crystallite size in order to understand their crystallographic structure, structural evolution, and degree of graphitization [11]. Analysis of the width of the Raman G peak demonstrated that samples of similar crystallographic properties were distinguishable through their degree of graphitization; whereby a decrease in $G$ peak width is associated with an increased degree of graphitization. Niwase \& Tanabe used Raman to study HOPG irradiated by $\mathrm{D}^{+}$and $\mathrm{He}^{+}$ions; the HOPG became amorphous at a critical dose, which increased with increasing temperature [12]. Through analysis of the relationship between the width of the G peak and the $\mathrm{I}_{\mathrm{D}} / \mathrm{I}_{\mathrm{G}}$ peak intensity ratio, three stages of damage were identified: firstly, the accumulation of defects within the basal plane; secondly the introduction of basal plane fragmentation and increased tortuosity; and finally, amorphization.

Irradiation-induced changes in the crystal lattice play an important role in the moderating properties of nuclear graphite. The displacement of carbon atoms under irradiation leads to the clustering of interstitials between basal planes resulting in c-direction expansion and a-direction contraction [1,13-15]. With increasing dose during reactor operation, the rate of contraction in the a-direction reduces, and eventually the graphite starts to experience net expansion; the critical point at which this reversal occurs is known as "turnaround" which varies with operating temperature [16].

Studies using electrons and ions to induce radiation damage have improved our understanding of dislocation structures and local bonding in irradiated graphites [12,17-21]. This is particularly useful because the availability of data for neutron irradiated specimens is limited. Recent work by Karthik et al. presented the microstructural changes occurring in graphite grades NBG-18 and IG-110 as a result of neutron irradiation [8]. No significant changes were reported for low dose specimens ( $1.54 \mathrm{dpa}$ at $430{ }^{\circ} \mathrm{C}$ and 1.91 $\mathrm{dpa}$ at $451^{\circ} \mathrm{C}$ ) of both grades. However, transmission electron microscopy (TEM) investigations of higher dose specimens (6.78 dpa at $678{ }^{\circ} \mathrm{C}$ and $6.70 \mathrm{dpa}$ at $674{ }^{\circ} \mathrm{C}$ ) provided evidence for the closure of microcracks (compared to unirradiated material), and lattice images revealed evidence for positive climb of prismatic edge dislocations and the consequent creation of new basal planes contributing to expansion in the c-direction. The present work aims to extend this to the study of micro to nanostructural changes in neutron irradiated PCEA and PCIB nuclear graphites.

\section{Experimental}

Both PCEA and PCIB graphites are new grades developed recently by GrafTech, Inc. and are being considered for use in the 4th generation of high temperature graphite moderated nuclear reactors. The as-received irradiated specimens were $6 \mathrm{~mm}$ high $\times 12 \mathrm{~mm}$ diameter cylinders. PCEA is petroleum-coke-based, contains medium-sized spherical and needle-like grains $(360 \mu \mathrm{m}$ - $800 \mu \mathrm{m}$ ) and is manufactured via extrusion. PCIB is petroleumcoke-based, contains ultra-fine grains (ca. $20 \mu \mathrm{m}$ in length) and is manufactured via isomoulding $[7,22]$. Since PCEA is an extruded grade the unique direction is with-grain. PCIB has no extrusion direction as it is an isomoulded grade so its unique direction is against-grain. The irradiation conditions for these samples are detailed in Table 1. Further information about the specimens' irradiation environment can be found in Refs. [22-24].

Both irradiation temperature and received dose influence the structure of graphite; this is demonstrated with the varying doses at which turnaround (the point at which irradiation induced net shrinkage stops, and net expansion towards the original dimensions begins) is reached for differing irradiation temperatures $[16,25]$. With decreasing temperature, the point of turnaround occurs at higher doses. The authors are not aware of any published turnaround data for irradiated PCEA and PCIB but it is known that none are beyond turnaround. However, parallels can be drawn with similar graphite grades. IG-110 is a fine grained isomoulded graphite, used as a reference grade and will be compared to the fine grained isomoulded PCIB specimens investigated in this work. Ishiyama et al. showed turnaround for IG-110 to occur at ca. $15 \mathrm{dpa}$ for an irradiation temperature of $600{ }^{\circ} \mathrm{C}$ [25]. Since the PCIB specimens investigated are at temperatures and, particularly, doses below this it is reasonable to assume none of the samples have undergone turnaround, i.e. they are in the shrinkage phase. Gilsocarbon is a medium grain isomoulded graphite used for the second generation of reactors (principally AGRs) and will be compared to the medium grained extruded PCEA specimens investigated in this work. A study by Hall et al. showed turnaround for Gilsocarbon to occur at ca. $6.5 \mathrm{dpa}$ for an irradiation temperature of $600^{\circ} \mathrm{C}$ and ca. $8.5 \mathrm{dpa}$ for an irradiation temperature of $430^{\circ} \mathrm{C}$ [16]. From this, we can postulate that specimen PCEA6.8 is approximately at the turnaround point and specimen PCEA1.5 is before the turnaround point, i.e. in the shrinkage phase.

\subsection{Polarized light microscopy}

Virgin samples of $10 \mathrm{~mm}$ high $\times 30 \mathrm{~mm}$ diameter were prepared for polarized light microscopy (PLM) by mounting, grinding and polishing. Representative PLMs of the virgin specimens are shown in Fig. 1. To prevent degradation of the surface and pore walls during polishing, samples were impregnated with EpoMet $\mathrm{F}$ resin. For grinding, Apex diamond grinding discs (DGD Yellow) equipped with $35 \mu \mathrm{m}$ abrasive diamonds were used. An EcoMet 250 grinder-polisher was then run in single force mode and an individual force of $20 \mathrm{~N}$ was applied to each specimen. This was followed by three polishing steps: TexMet $\mathrm{C}$ with $9 \mu \mathrm{m}$ abrasive MetaDi supreme water based fluid; Trident cloth with $3 \mu \mathrm{m}$ abrasive MetaDi supreme water based fluid; and finally, a micro cloth was used to

Table 1

Received neutron dose and irradiation temperature of specimens.

\begin{tabular}{llll}
\hline Grade & Specimen ID & $\frac{\text { Dose }}{\mathrm{dpa}}$ & $\frac{\text { Temperature }}{$\cline { 3 - 3 }} \\
& & ${ }^{\circ} \mathrm{C}$ \\
\hline PCEA & PCEA1.5 & 1.5 & 350 \\
& PCEA6.8 & 6.8 & 670 \\
PCIB & PCIB1.5 & 1.5 & 350 \\
& PCIB4.0 & 4.0 & 535 \\
& PCIB6.8 & 6.8 & 655 \\
\hline
\end{tabular}


polish for two minutes in a $0.05 \mu \mathrm{m}$ master prep suspension. Following polishing, the samples were rinsed with water and ethanol and dried before observation with an Olympus BX51 Optical Microscope at 50× magnification (pixel resolution $0.7 \mu \mathrm{m}$ ). Image $\mathrm{J}$ was used to determine the size and shape of the filler particles and porosity within samples. To analyse micrographs for porosity a threshold was set in the range 50-225 to capture all apparent pores in the image. The image was then segmented and contrast converted. The minimum pores size identified were in the range of $5 \mu \mathrm{m}^{2}(3 \times 3$ pixels $)$.

\subsection{SEM}

SEM was performed on a Carl-Zeiss LEO 1530 FEG-SEM for virgin samples, and a FEI Nova 200 Nanolab dual-beam FEG-SEM/FIB for the irradiated samples. In both cases, secondary electron images were obtained using an in-lens detector at an operating voltage of $5 \mathrm{kV}$. The images of the virgin samples in Fig. 2 were on the polished sections used for optical microscopy. For the images shown in Figs. 3 and 4, the samples were analysed as received after cleaning using isopropanol to remove any surface dust; no coating was necessary due to high surface conductivity. Image analysis measurements were undertaken on four SEM images providing a total surface area of $9.4 \mathrm{~mm}^{2}$; this provided a 2D analysis of the surface pores that only revealed qualitative changes in surface porosity and did not consider the internal structure or the internal dimension of pores and their number density (i.e. hidden pores). Furthermore, due to resolution limitations, the possible presence of surface nanopores was not considered.

\section{3. $X R D$}

XRD measurements were performed on a PANalytical X'pert Pro diffractometer ( $\mathrm{Cu}$ anode $40 \mathrm{keV}, 40 \mathrm{~mA}, \lambda=1.545 \AA$ ) ) working in $2 \theta$ Bragg geometry. XRD patterns were collected from $20^{\circ}$ to $90^{\circ} 2 \theta$ in continuous scanning mode with an interval of $0.066^{\circ}$ at a speed of $300 \mathrm{~s}$ (time/step). Data analysis was performed using X'pert High Score Plus software to subtract background and determine peak positions and widths. Instrumental broadening was determined from the line profile of a standard silicon specimen and was subtracted in quadrature; strain broadening was subtracted (where possible) using a Williamson-Hall plot [26]. Coherence lengths were calculated from the remaining broadening using Scherrer's equation, with shape factors $\mathrm{K}=1.74\left(\mathrm{~L}_{\mathrm{a}}\right)$ and $\mathrm{K}=0.9\left(\mathrm{~L}_{\mathrm{c}}\right)$.

\subsection{Raman}

Raman experiments were carried out at room temperature, using a Renishaw spectrometer with a CCD detector and a modified optical microscope (of $1 \mu \mathrm{m}$ resolution). The spectra were recorded using an $\mathrm{Ar} / \mathrm{Kr}$ ion laser of $\lambda=514.5 \mathrm{~nm}$ and a $50 \times$ objective was used to focus the laser onto the samples. The laser power was adjusted to $24 \mathrm{~mW}$, and the spectral integration time was $30 \mathrm{~s}$ with two spectra per accumulation. A Raman spectral range of $1000-3200 \mathrm{~cm}^{-1}$ was recorded for more than 40 spectra per sample. Due to the small grain size, it was not possible to target specific filler/binder phases. Spectra were fitted with Origin Lab 9.1 using Breit-Wigner-Fano (BWF) function for the fitting of the $G$ peak, and a Lorentzian fit for the D peak. Previous studies have shown this combination of peak fit functions provides the best match to the raw spectra $[27,28]$.

\subsection{TEM/EELS}

TEM specimens were prepared using an FEI Nova200 dual beam SEM/FIB fitted with a Kleindiek micromanipulator for in situ lift out. The analysed areas had varying thickness; but always below $150 \mathrm{~nm}$. A gallium ion beam energy of $30 \mathrm{kV}$ and beam currents between $5000 \mathrm{nA}$ and $100 \mathrm{nA}$ were used, except for the final cleaning step where an energy of $5 \mathrm{kV}$ and current of $29 \mathrm{pA}$ were used in order to minimise the effects of beam damage and redeposition of sputtered material. FIB sections were all collected from filler particles, allowing for a fair comparison between specimens.

Room temperature TEM and electron energy loss spectroscopy (EELS) data were collected using a Philips CM200 FEGTEM operated at $80 \mathrm{kV}$ to minimise the effect of beam damage. The electron flux was of the order $10^{18}$ electrons $\mathrm{cm}^{-2} \mathrm{~s}^{-1}$ and the EELS energy resolution was $0.7-0.8 \mathrm{eV}$. Images and spectra were captured using a Gatan Imaging Filter (GIF) 200 with a 1 mega-pixel slow scan CCD array. EEL spectra were collected at the magic angle conditions to mitigate the effects of orientation on spectral shape [29]. The high thermal conductivity of graphite prevents beam induced localized heating [30].

All electron micrographs were subject to the PyroMaN image analysis technique detailed in DaCosta et al. and used on electronirradiated graphite by Mironov et al. [17,31]. Since the measurement of fringe length is ultimately limited by the width of the micrograph, TEM images were cropped to be the same size, with approximately the same resolution, ensuring a fair comparison between fringe length values. The d-spacings were measured from the spacing of (002) spots in selected area electron diffraction (SAED) patterns by measuring peak to peak distances from a linear intensity profile.

\section{Results and discussion}

\subsection{PLM and SEM}

Fig. 1 (a) shows a PLM of virgin PCEA which exhibited a wide variation in the shapes and sizes of filler particles. Almost $60 \%$ of
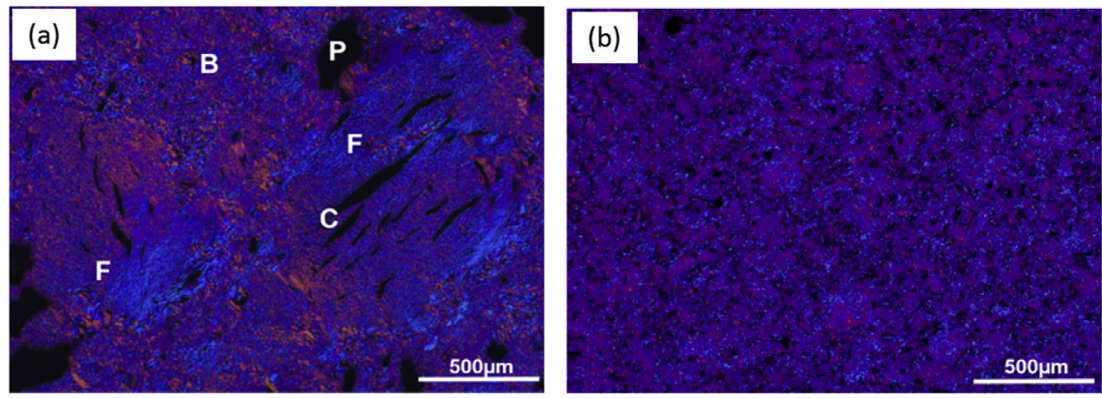

Fig. 1. PLMs of (a) virgin PCEA showing filler particles (F), binder phase (B), porosity (P) and shrinkage cracks (C), and (b) virgin PCIB showing ultrafine grains. 

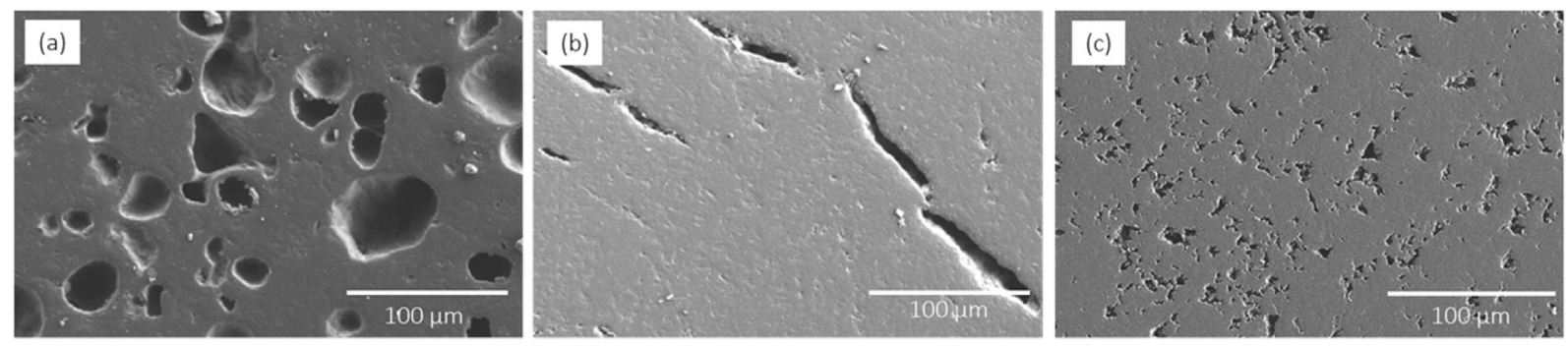

Fig. 2. Scanning electron micrographs of polished sections of: (a) virgin PCEA binder particle, (b) virgin PCEA filler particle and (c) virgin PCIB.
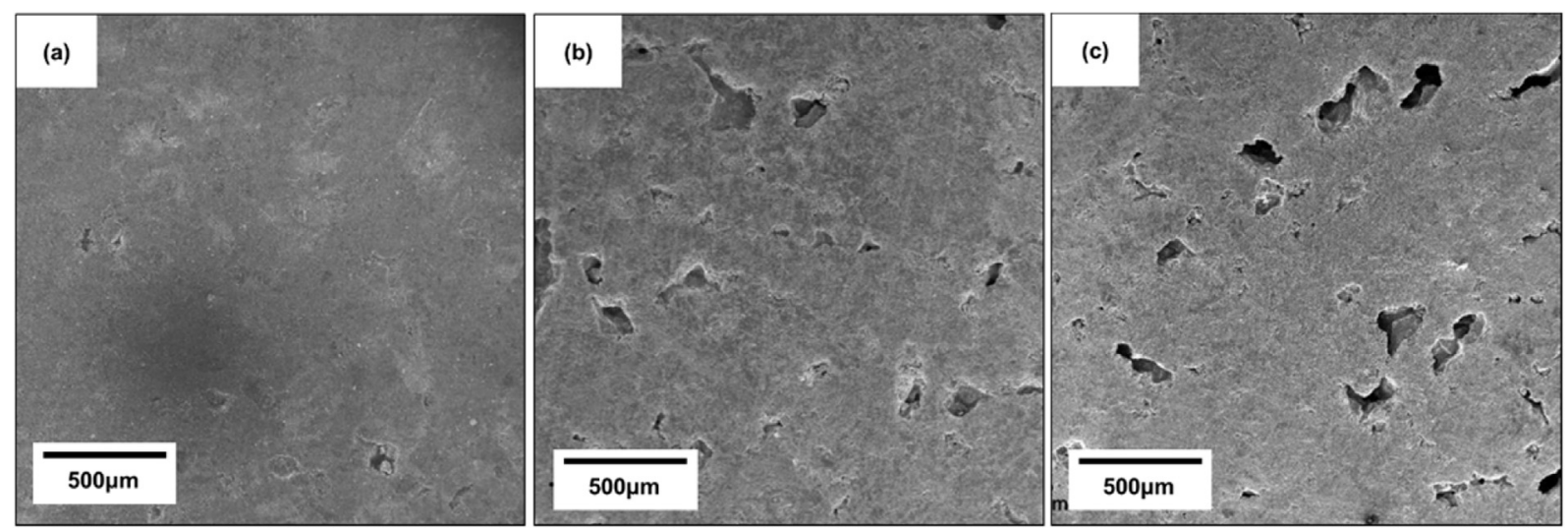

Fig. 3. SEM images of as-received samples: (a) virgin PCEA, (b) PCEA1.5 and (c) PCEA6.8.
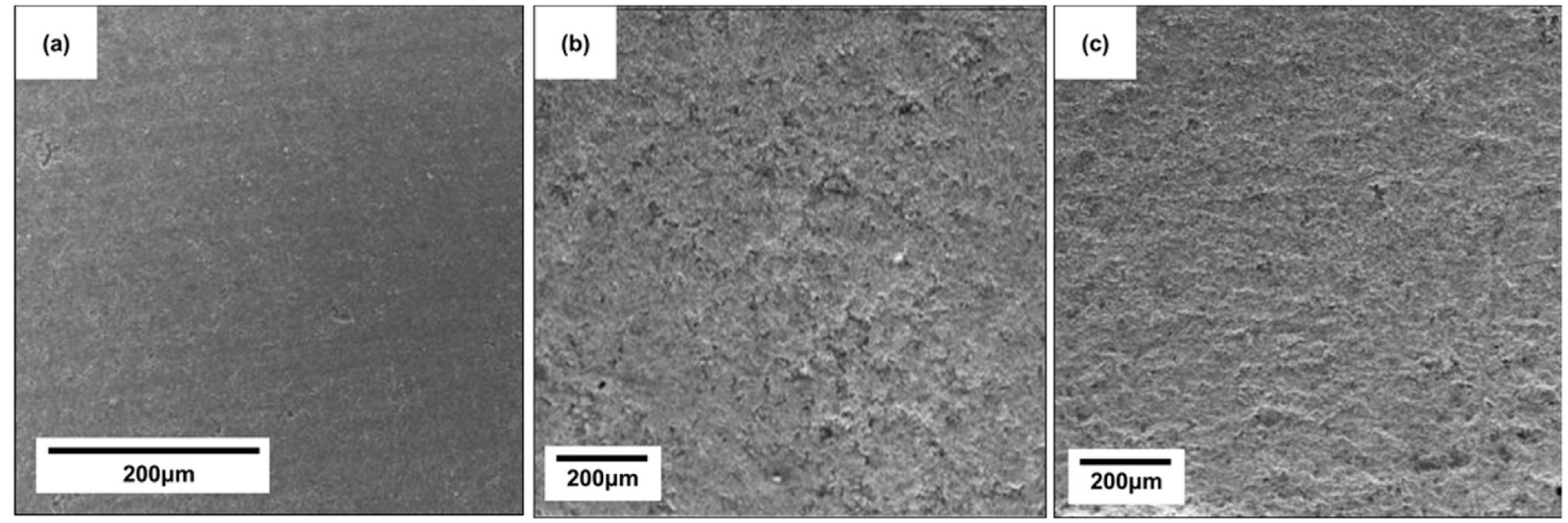

Fig. 4. SEM images of as-received samples: (a) virgin PCIB, (b) PCIB1.5 and (c) PCIB6.8.

the particles were needle-shaped with a mean length of $565 \pm 22 \mu \mathrm{m}$ and had an aspect ratio of $4 \pm 0.3$, whilst the spherical particles had an average diameter of ca. $475 \mu \mathrm{m}$. In contrast, from the micrographs of PCIB (e.g. Fig. 1 (b)), it proved more difficult to distinguish whether an area contained filler or binder particles due to the fine microstructure. A significant variation in pore size, shape and orientation can be observed between PCEA and PCIB; the shape and orientation of porosity can often indicate whether a pore is within the filler particles or binder matrix. Virgin PCEA has an average porosity of $16.9 \%$ with spherical pores of ca. $2000 \mu \mathrm{m}^{2}$ in area and narrow crack-like pores of ca. $15 \mu \mathrm{m}$ average width. The porosity in virgin PCIB was lower (11.3\%) and pores were much smaller and of the order of ca. $25 \mu \mathrm{m}^{2}$ in average size.

Representative SEM images for both virgin (polished and unpolished specimens) and irradiated PCEA and PCIB (unpolished specimens) are displayed in Figs. 2-4 respectively. The large grain size of PCEA allowed for separate SEM images to be captured from filler and binder phases in the virgin specimen. The binder phase exhibits characteristic spherical pores, whereas the filler phase contains needle shaped pores. Significant changes in surface morphology can be observed with irradiation dose and temperature and, qualitatively, both graphite grades exhibited an increase in porosity following neutron irradiation. Increasing irradiation dose and temperature in PCEA led to increased pore density and increased average pore size; there appeared to be no preferential pore shape and orientation. Pores were also observed in irradiated PCIB and these were of the order of $\mu \mathrm{m}$ in size, with no specific shape, which made accurate pore measurement difficult. Further 
work is required to identify the nature, size and density of pores in irradiated specimens, and more precisely to investigate whether the surface pores are due to irradiation or the specimen preparation procedure.

\section{2. $X R D$}

XRD data from both virgin and irradiated PCIB and PCEA samples are shown in Fig. 5 and the results of analysis are shown in Table 2. Many peaks appear to broaden (e.g. (002) and (004)) or disappear (e.g. (103) and (006)) with irradiation dose, whilst some (e.g. (100)) change in peak position. The positions of the (100) and (110) reflections are associated with the a-lattice parameter and the (002), (004), and (006) reflections are associated with c-lattice parameter (and hence (002) interplanar spacing). The full width at half maximum (FWHM) of the (110) (or (100)) and (002) peaks correspond to the coherence lengths in the a-direction $\left(\mathrm{L}_{\mathrm{a}}\right)$ and $\mathrm{c}$ direction $\left(L_{c}\right)$, respectively. In this work the (110) peak has been used to measure changes in $\mathrm{L}_{\mathrm{a}}$. Although XRD for both graphite grades showed no significant changes in (002) interplanar spacing as compared to virgin specimens, the crystallite size for $\mathrm{L}_{\mathrm{a}}$ and $\mathrm{L}_{\mathrm{c}}$ reduced by $55 \%$ and $40 \%$ respectively for the lower dose PCEA1.5 and PCIB1.5 specimens. For higher dose PCEA6.8 PCIB6.8 specimens the change in $\mathrm{L}_{\mathrm{a}}$ was ca. $45 \%$, however measurements for $\mathrm{L}_{c}$ gave higher variability between grades; a $54 \%$ reduction in $\mathrm{L}_{\mathrm{c}}$ for PCEA and a $39 \%$ reduction in $\mathrm{L}_{\mathrm{C}}$ for $\mathrm{PCIB}$ (as compared to virgin specimens of the same grade).

These results show similar trends to the findings of Gallego discussed previously, but with slightly smaller crystallite size reductions in this work [9]. Bulk dimensional change of Gilsocarbon graphite irradiated between 3 and $10 \mathrm{dpa}$ at $650-750{ }^{\circ} \mathrm{C}$ by Marsden et al. and PCEA and PCIB irradiated between 6 and $10 \mathrm{dpa}$ at $750{ }^{\circ} \mathrm{C}$ by Vreeling et al. found higher levels of shrinkage in the with-grain direction (parallel to the extrusion direction) than the against-grain direction [32,33]. For the specimens in this paper this is also the case, however higher dose PCEA6.8 shows a more significant crystallite size reduction in the against grain direction, suggesting it is near turnaround, as proposed previously. According to Marsden et al. the preferred orientation of crystallites is associated with the grain direction and can be used to relate polycrystalline properties to crystalline properties.

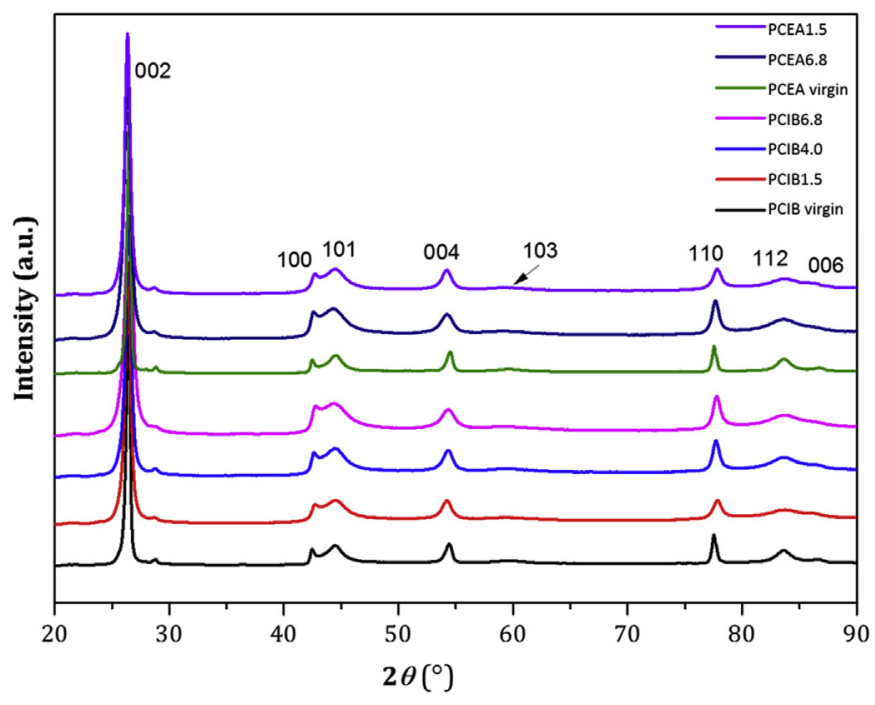

Fig. 5. Representative XRD patterns of virgin and irradiated PCIB and PCEA.

\subsection{Raman}

Representative first-order Raman spectra of virgin and irradiated PCIB and PCEA are shown in Figs. 6 and 7 and the data extracted from them by peak fitting is given in Table 3 . The wavenumber of the $G$ peak position in the spectra of irradiated specimens is higher than for virgin material, implying the fragmentation of crystallites following neutron irradiation (as observed by Ferrari et al. and in agreement with XRD [34]). According to Ferrari et al. this apparent shift is due to the nearby $\mathrm{D}^{\prime}$ peak at $1620 \mathrm{~cm}^{-1}$ gaining intensity and contributing to the $G$ peak. However, since peak fittings have been performed this suggests that the $G$ peak resonance actually increases in wavenumber with irradiation. The spectra of irradiated specimens also show an increase in the FWHM of the $G$ peak of between 2 and 5 times and an increase in $\mathrm{I}_{\mathrm{D}} / \mathrm{I}_{\mathrm{G}}$ ratio of up to 4 times relative to the virgin specimen. The most significant changes are observed in PCIB1.5 and PCEA1.5, however in the spectrum of PCEA1.5 it must be noted that no apparent $\mathrm{D}^{\prime}$ peak was present which was assumed to be subsumed under the $G$ peak that has increased in wavenumber. With increasing dose and irradiation temperature (PCIB4.0, PCIB6.8 and PCEA6.8), the narrowing of peaks, reduction in $\mathrm{I}_{\mathrm{D}} / \mathrm{I}_{\mathrm{G}}$ ratio and a lower wavenumber $\mathrm{G}$ peak position, suggest that the higher irradiation temperature $\left(655^{\circ} \mathrm{C}\right)$ allows defects to anneal. These results are in line with previous studies $[7,9,17,35]$.

\subsection{TEM/EELS}

Representative TEM micrographs and SAED patterns from all virgin and irradiated specimens are shown in Fig. 8. The d-spacing of basal planes was measured from the spacing of (002) diffraction spots in SAED patterns; at least five SAED patterns were collected for each specimen and the results are displayed in Fig. 9(a). Due to the selected area aperture required for SAED, the quoted values for $\mathrm{d}$-spacing are an average over a specimen area of $10^{5} \mathrm{~nm}^{2}$. In all cases, the irradiated specimens have a higher d-spacing than the virgin specimens implying irradiation induced expansion in the $c$ direction. The (002) inter-planar spacing measured by XRD (Table 2 where $\mathrm{d}_{002}$ ranges from 0.337 to $0.338 \mathrm{~nm}$ ) show consistently lower values compared to SAED results. This is potentially due to the larger volumes analysed by XRD, differences in specimen preparation (e.g. strain relief in thin specimens), or the result of a systematic error (e.g. experimental calibration). A discrepancy between d-spacings derived from different techniques was also found by Muto \& Tanabe, whose results from Fourier transformation of local TEM lattice images were higher than those derived from larger area SAED analysis [36].

PCIB4.0 shows a reduction in d-spacing compared to its lower and higher dose neighbours. This may indicate a point at which the annealing effects (at $535^{\circ} \mathrm{C}$ ) become more prominent, despite the relatively higher dose (4 dpa). PCIB6.8 exhibits a higher d-spacing than PCIB4.0 suggesting that the higher dose (6.8 dpa) has more influence on the structure and prevents recovery, despite the increased contribution of thermal annealing at a higher temperature $\left(655^{\circ} \mathrm{C}\right)$. PCEA6.8 shows a slightly lower value for d-spacing than PCEA1.5. The closure of microcracks at turnaround restricts further expansion in the c-axis which could explain the lower measured values for d-spacing in PCEA6.8 (thought to be near turnaround). In contrast, the continued c-axis expansion for PCIB6.8 (reflected through larger measurements for d-spacing) suggests this specimen is indeed before turnaround, as previously suggested. These results highlight the significance operating temperature and the point of turnaround has on structural change.

The data extracted from TEM lattice images for (002) fringe length (L2) is displayed in Fig. 9(b). At least ten micrographs were 
Table 2

Averaged data extracted from XRD patterns of specimens of virgin and irradiated PCEA and PCIB.

\begin{tabular}{|c|c|c|c|c|c|c|c|}
\hline \multirow[t]{2}{*}{ Specimen } & \multirow{2}{*}{$\begin{array}{l}\text { Dose } \\
\overline{\text { dpa }}\end{array}$} & \multirow{2}{*}{$\begin{array}{l}\text { Temp. } \\
{ }^{\circ} \mathrm{C}\end{array}$} & \multirow{2}{*}{$\begin{array}{l}\text { c lattice parameter } \\
\text { from }(002) \\
\AA\end{array}$} & \multirow{2}{*}{$\begin{array}{l}\text { a lattice parameter } \\
\text { from }(100) \\
\AA\end{array}$} & \multirow{2}{*}{$\begin{array}{l}\mathrm{L}_{\mathrm{c}} \\
\bar{\AA}\end{array}$} & \multirow{2}{*}{$\begin{array}{l}\mathrm{L}_{\mathrm{a}} \\
(110) \\
\AA\end{array}$} & \multirow{2}{*}{$\begin{array}{l}\mathrm{L}_{\mathrm{a}} \\
(100) \\
\AA\end{array}$} \\
\hline & & & & & & & \\
\hline PCEA & - & - & $6.760 \pm 1 \times 10^{-4}$ & $2.461 \pm 3 \times 10^{-3}$ & $257 \pm 4$ & $643 \pm 2$ & $434 \pm 54$ \\
\hline PCEA1.5 & 1.5 & 350 & $6.776 \pm 4 \times 10^{-4}$ & $2.452 \pm 5 \times 10^{-3}$ & 140 & 267 & 148 \\
\hline PCEA6.8 & 6.8 & 670 & $6.777 \pm 4 \times 10^{-4}$ & $2.457 \pm 7 \times 10^{-3}$ & 118 & 366 & 291 \\
\hline PCIB & - & - & $6.754 \pm 2 \times 10^{-4}$ & $2.461 \pm 2 \times 10^{-3}$ & $231 \pm 20$ & $600 \pm 45$ & $420 \pm 29$ \\
\hline PCIB1.5 & 1.5 & 350 & $6.766 \pm 4 \times 10^{-4}$ & $2.453 \pm 3 \times 10^{-3}$ & 147 & 284 & 254 \\
\hline PCIB4.0 & 4.0 & 535 & $6.752 \pm 3 \times 10^{-4}$ & $2.451 \pm 4 \times 10^{-3}$ & 158 & 321 & 223 \\
\hline PCIB6.8 & 6.8 & 655 & $6.731 \pm 5 \times 10^{-4}$ & $2.452 \pm 2 \times 10^{-3}$ & 140 & 312 & 204 \\
\hline
\end{tabular}
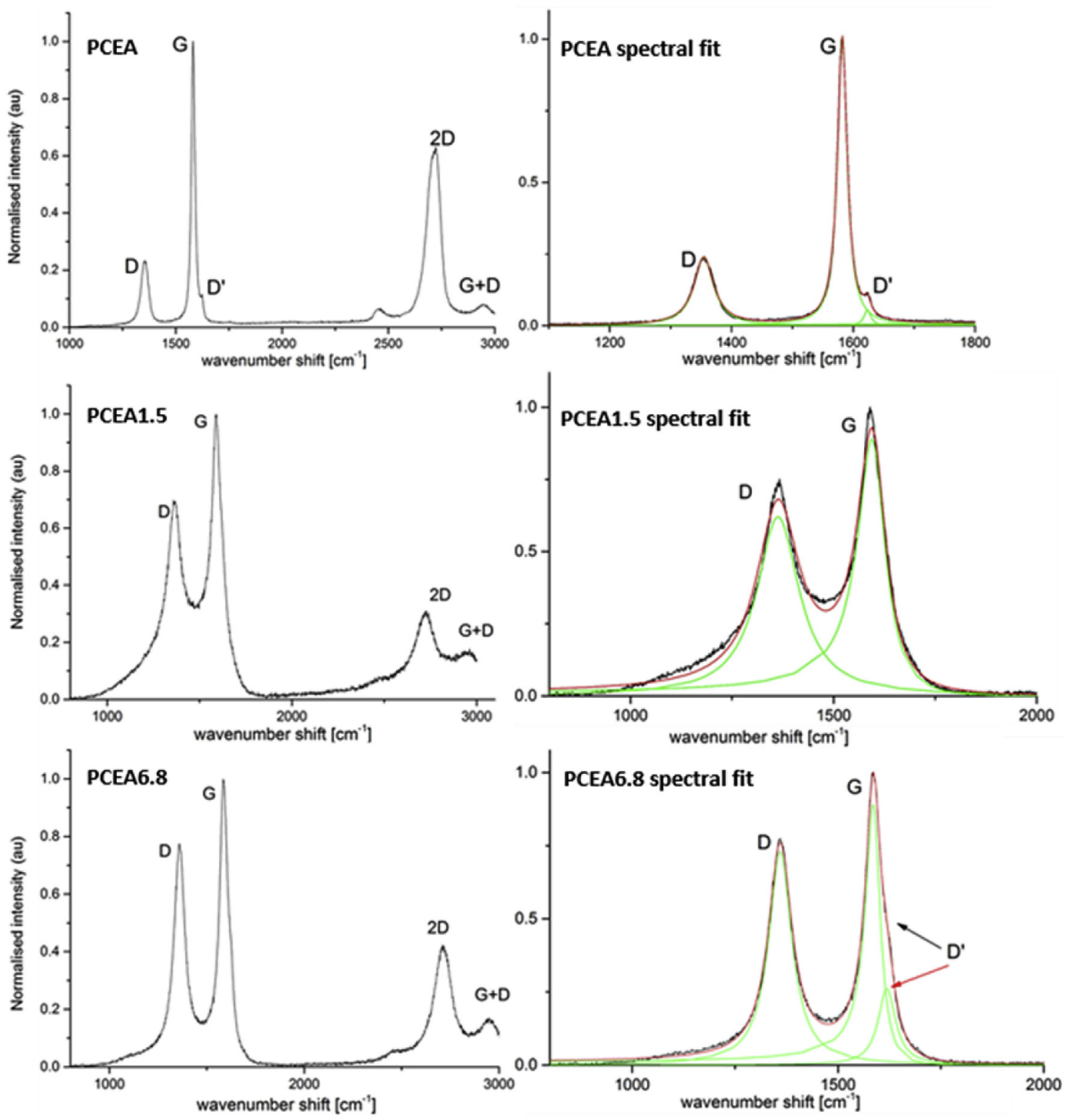

Fig. 6. Representative first-order Raman spectra of virgin and irradiated PCEA.

analysed for each irradiated specimen. The image analysis technique could not be applied to lattice images of virgin specimens since it requires both ends of a basal plane to be within the image frame (many of the highly ordered long fringes in virgin specimens go beyond the image frame and are therefore not extracted for analysis by the software). In general, there is no significant trend between fringe length and received dose and micrographs were highly variable across all specimens, reflected through the large error bars. However, for both grades, there is a suggestion of reducing fringe length with increasing dose. The data extracted for 

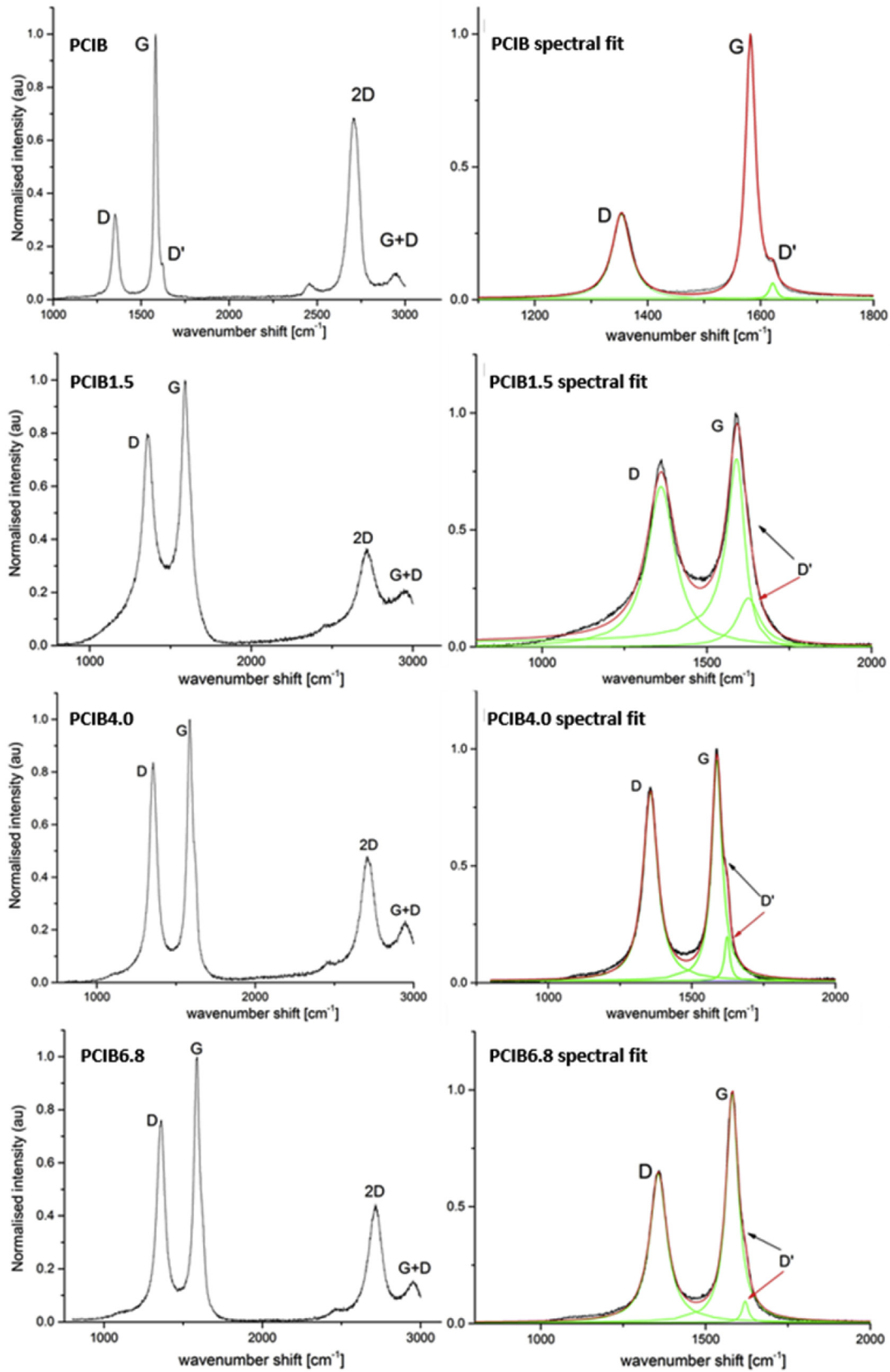

Fig. 7. Representative first-order Raman spectra of virgin and irradiated PCIB. 
Table 3

Averaged data extracted from over 40 Raman spectra per specimen of virgin and irradiated PCEA and PCIB.

\begin{tabular}{|c|c|c|c|c|c|c|}
\hline \multirow[t]{2}{*}{ Specimen } & \multirow{2}{*}{$\frac{\text { Dose }}{\mathrm{dpa}}$} & \multirow{2}{*}{$\frac{\text { Temp. }}{{ }^{\circ} \mathrm{C}}$} & \multirow[t]{2}{*}{$\underline{\mathrm{I}_{\mathrm{D}} / \mathrm{I}_{\mathrm{G}}}$} & \multirow{2}{*}{$\frac{\mathrm{G} \text { FWHM }}{\mathrm{cm}^{-1}}$} & \multirow{2}{*}{$\frac{\mathrm{G} \text { peak }}{\mathrm{cm}^{-1}}$} & \multirow{2}{*}{$\frac{\text { D peak }}{\mathrm{cm}^{-1}}$} \\
\hline & & & & & & \\
\hline PCEA & - & - & $0.1-0.3$ & $19.7 \pm 1$ & 1581.8 & 1354.3 \\
\hline PCEA1.5 & 1.5 & 350 & $0.6-0.8$ & $90.6 \pm 9$ & 1593.1 & 1364.8 \\
\hline PCEA6.8 & 6.8 & 670 & $0.5-0.9$ & $48.5 \pm 5$ & 1587.2 & 1361.6 \\
\hline PCIB & - & - & $0.1-0.3$ & $19.9 \pm 1$ & 1582.4 & 1354.2 \\
\hline PCIB1.5 & 1.5 & 350 & $0.7-1.1$ & $68.3 \pm 7$ & 1590.0 & 1362.3 \\
\hline PCIB4.0 & 4.0 & 535 & $0.6-1.0$ & $46.9 \pm 3$ & 1587.3 & 1358.8 \\
\hline PCIB6.8 & 6.8 & 655 & $0.6-1.0$ & $46.8 \pm 3$ & 1586.5 & 1358.4 \\
\hline
\end{tabular}
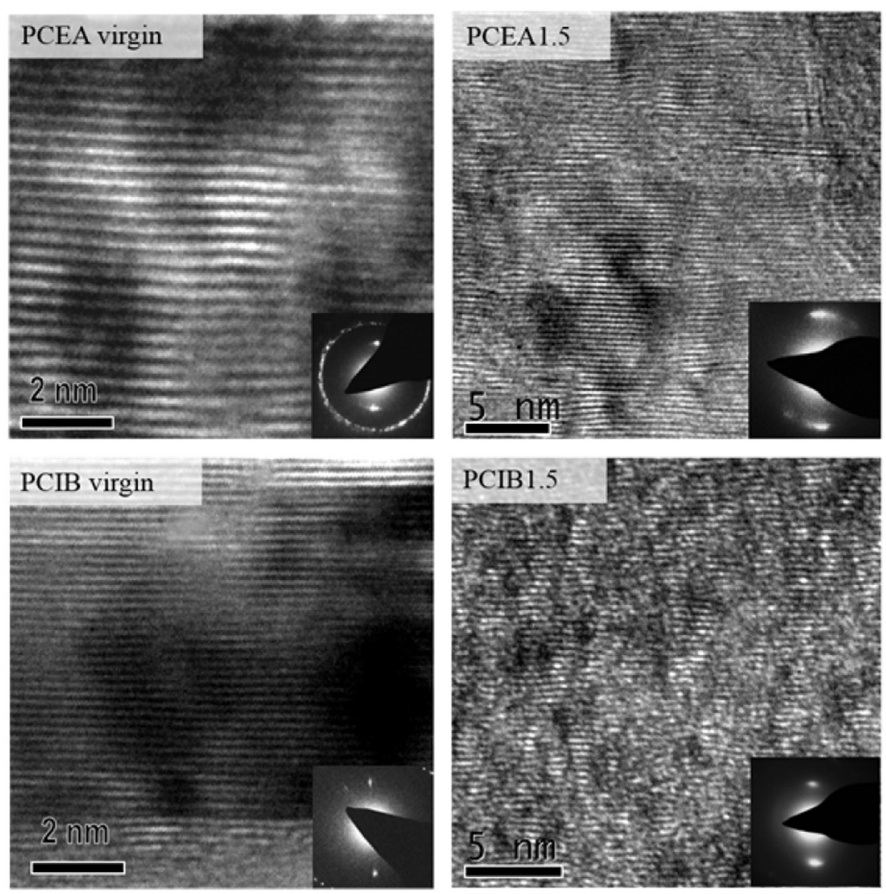
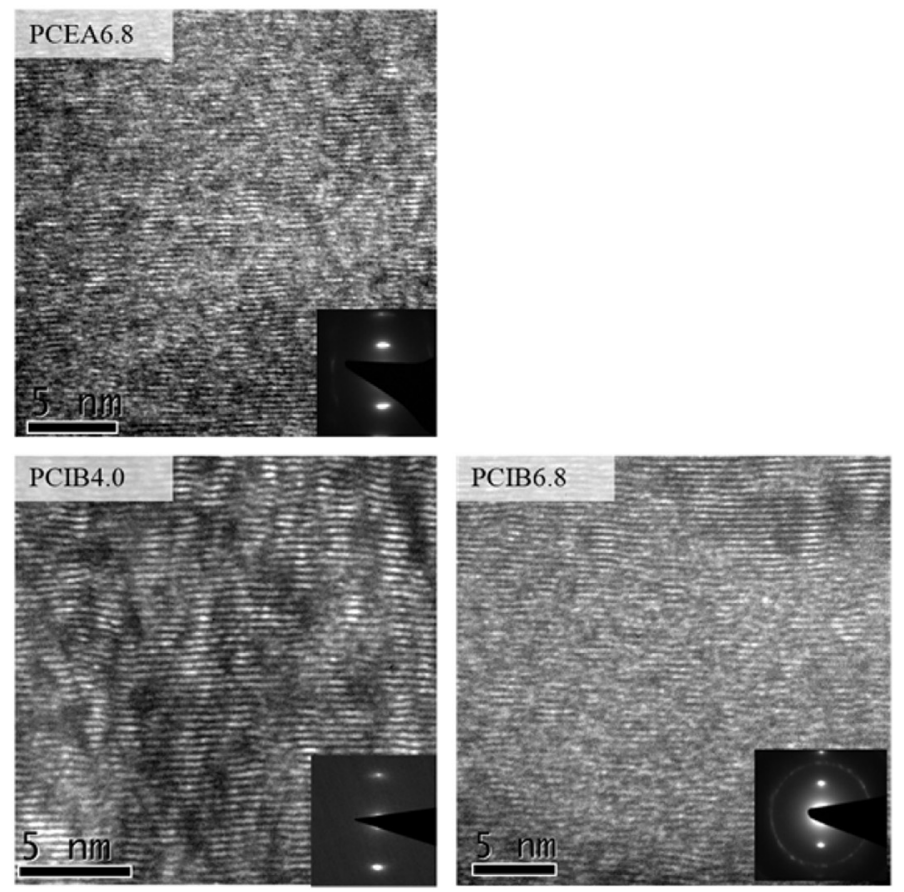

Fig. 8. Representative TEM lattice images and corresponding SAED patterns of all specimens.

tortuosity and misorientation are shown in Fig. 9 (c) and (d), respectively, and there are no obvious trends for either parameter. In general terms, the extent of damage appears to be highly variable throughout each specimen (reflected through the large error bars) and is extremely site specific across the specimen, potentially due to the anisotropic nature of nuclear graphite and nanostructural heterogeneity. In some cases, the opposite of what is expected is observed; the tortuosity and misorientation decreases with increasing dose for PCIB specimens; potentially an effect of thermal annealing at higher temperatures.

Similar lattice image analysis was applied to nuclear grade graphite subject to controlled electron irradiation damage in a previous study by Mironov et al. [17]. This demonstrated that the analysis technique can indeed detect subtle changes in the lattice structure. Although every effort was made in this study to allow for a fair comparison (consistency in TEM imaging conditions, image size, and resolution) it appears that the anisotropy of irradiated nuclear graphite makes for highly variable data which must be interpreted with caution.

Representative EEL carbon K-edge spectra from PCEA and PCIB are shown in Fig. 10. The $\pi^{*}$ and $\sigma^{*}$ peak intensities were analysed following the five Gaussian fitting method used in Refs. [3,17] and data was normalised to $100 \% \mathrm{sp}^{2}$ for HOPG. Using this method, it was possible to derive that virgin PCIB and PCEA exhibited ca. 90\% planar $\mathrm{sp}^{2}$-bonded carbon.

As seen in Fig. 11(a), little change in planar $\mathrm{sp}^{2}$-bonded carbon content was observed following neutron irradiation for both graphite grades. As with the TEM imaging and diffraction results, the data was highly variable between different areas within each specimen, evidenced by the relatively large error bars. PCEA6.8 and PCIB6.8 showed signs of structural recovery where $\mathrm{sp}^{2}$ values were calculated to be slightly higher than, or close to, values associated with lower dose/temperature specimens (PCEA1.5 and PCIB1.5). It is thought that this is due to the higher irradiation temperatures allowing for slight thermal annealing. In general, the $\mathrm{sp}^{2}$ values have not reduced as much as those from the room temperature electron irradiation studies in [17], where reductions in $\mathrm{sp}^{2}$ content of up to $24 \%$ (at $0.32 \mathrm{dpa}$ ) were observed.

Analysis of the position of the $(\pi+\sigma)$ volume plasmon peak $\left(E_{p}\right)$ in the EEL low loss spectra showed a slight difference between virgin and irradiated specimens (Fig. 11(b)): for both graphite grades, the average position of the plasmon peak decreased by ca. 1 $\mathrm{eV}$. This implied a slight reduction in density following neutron irradiation, possibly as a result of an increase in low density material at crystallite grain boundaries following crystallite fragmentation (as observed from XRD and Raman) and/or an increase in 

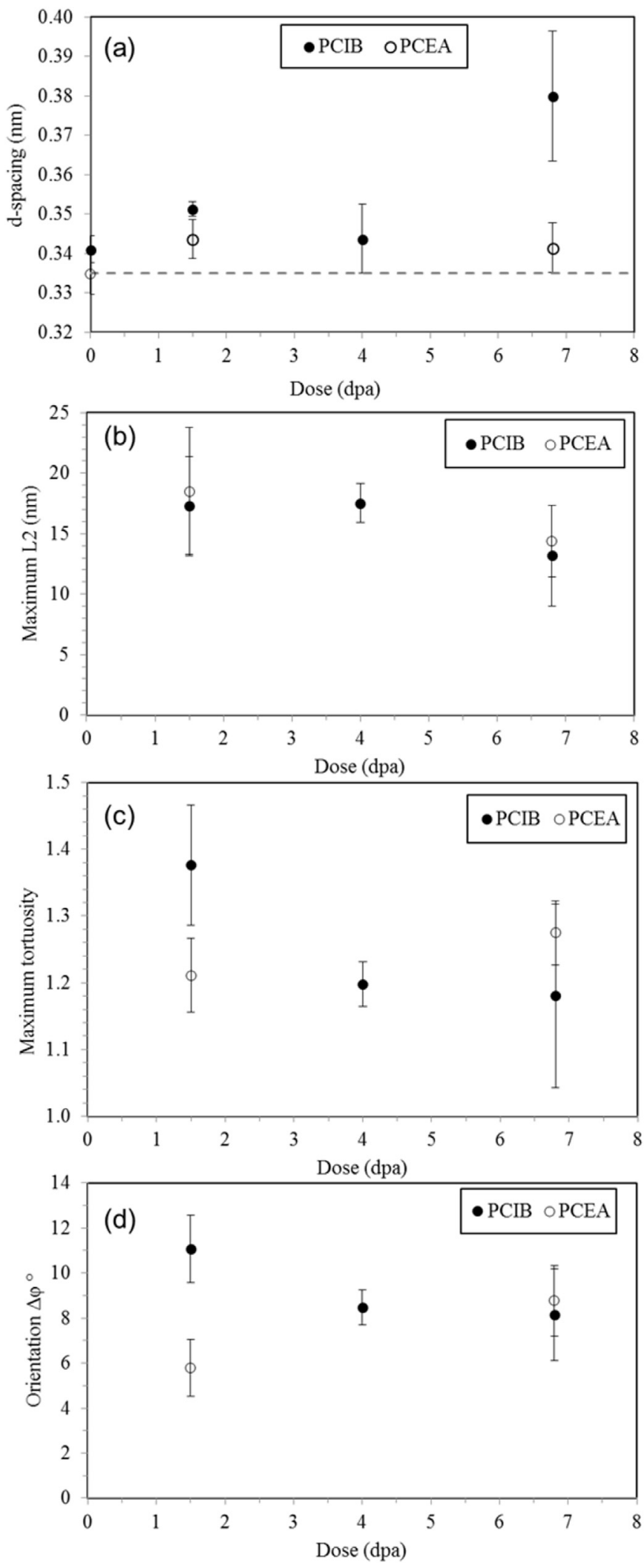

Fig. 9. Extracted data from TEM lattice images and SAED patterns (a) d-spacing (dashed line represents d-spacing in pristine graphite), (b) fringe length, (c) tortuosity and (d) orientation. Error bars represent analytical error following the analysis of multiple micrographs/diffraction patterns per specimen.

nanoporosity [37]. However, the data was also highly variable over different areas. In the most extreme cases, the $(\pi+\sigma)$ plasmon peak
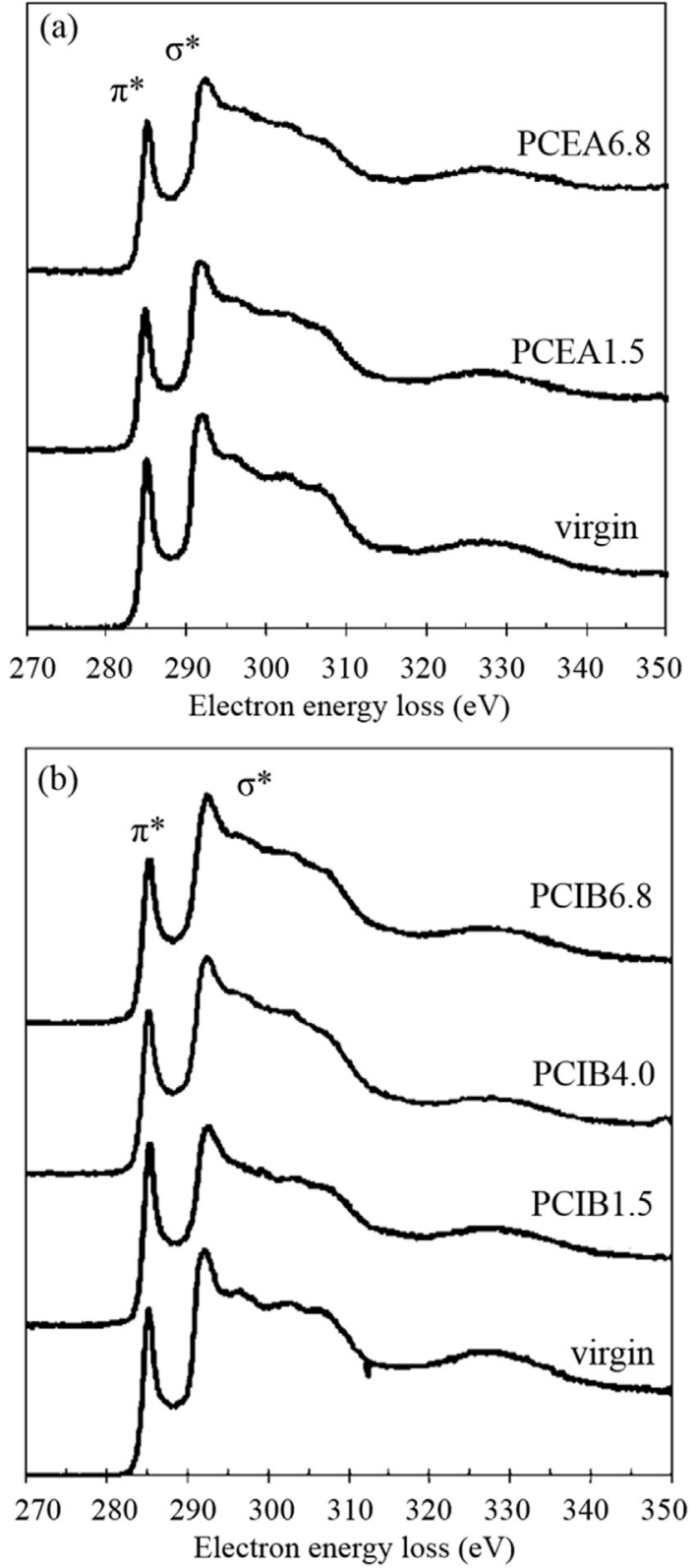

Fig. 10. Representative core loss EEL spectra for virgin and irradiated (a) PCEA and (b) PCIB.

position varied by $3 \mathrm{eV}$ within the same specimen. Unlike the carbon $\mathrm{sp}^{2}$-content data, this data shows little evidence for the thermal recovery of high dose, high temperature specimens, possibly due to the introduction of irradiation induced microcracks. Due to the high variability in this data, further analysis of more samples is required to improve the confidence of this interpretation.

\section{Conclusions}

PLMs of virgin PCEA showed a medium grained microstructure with a wide variety of filler particles, from ca. $565 \mu \mathrm{m}$ long needles to ca. $475 \mu \mathrm{m}$ spheres, and a porosity of $16.9 \%$. Micrographs of virgin PCIB showed a fine microstructure with grains of ca. $20 \mu \mathrm{m}$ in diameter and a porosity of ca. 11.3\%. SEM images showed significant changes in surface morphology with irradiation dose and 

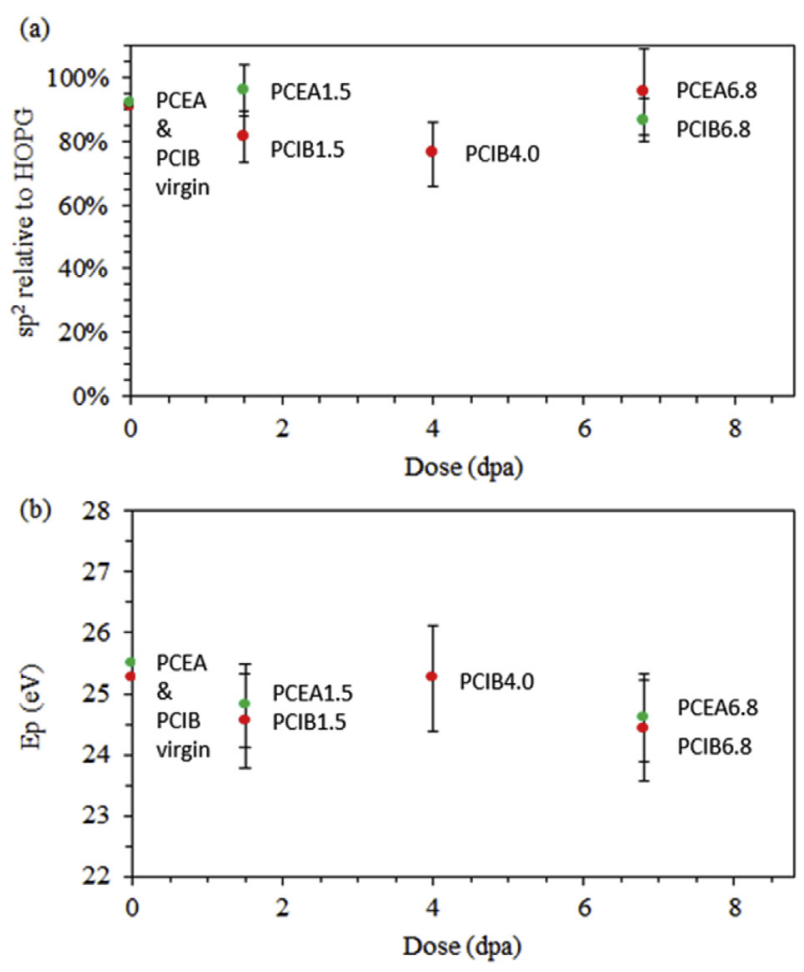

Fig. 11. Averaged EELS data ((a) carbon $\mathrm{sp}^{2}$ content (b) plasmon energy) extracted from 30 spectra per specimen for virgin and irradiated PCEA and PCIB. Error bars represent analytical error following the analysis of at least 15 spectra per specimen.

temperature where both grades exhibited an increase in porosity (both density and pore size) following neutron irradiation.

XRD, Raman, TEM, SAED and EELS measurements of the irradiated specimens shows that neutron irradiation induces basal plane and crystallite fragmentation; in general lower dose/temperature specimens (PCEA1.5 and PCIB1.5) tended to exhibit higher structural damage (such as lower $\mathrm{sp}^{2}$ content, higher d-spacing, and reduced crystallite size) than the relatively higher dose/temperature specimens (PCEA6.8 and PCIB6.8). The d-spacing of PCEA6.8 was less than PCIB6.8 which was thought to be due to the former being at turnaround and therefore expansion being restricted by the closure of cracks. The structural changes measured from XRD and Raman were more pronounced than those measured from TEM, SAED and EELS however comparisons can be made. Evidence for the reduction of $\mathrm{L}_{\mathrm{a}}$ and $\mathrm{L}_{\mathrm{c}}$ (from XRD measurements) and the fragmentation of crystallites (from Raman measurments) following neutron irradiation supports the observations of irradiation induced in-plane defects and the curvature/rearrangement of the layered basal plane structure in TEM images. In addition, the reduction in planar- $\mathrm{sp}^{2}$ content (thought to be due to the buckling of basal planes and the introduction of non-six-membered rings) from EELS measurements further supports this observation.

While the finer grained PCIB contained smaller pores, no other obvious differences in the microstructure were observed associated with grain size. The similarity in nanostructural response to neutron irradiation between the two grades studied suggests that grain size (fine or medium) and manufacture technique (extruded or isomoulded) has no significant effect on the nanoscale. Since any differences in the nanostructure are below the grain mesostructure they are therefore not thought to be related to grain size by crystallite size/shape/orientation.

The subtle changes observed between specimens of different irradiation dose and temperature highlights the heterogeneity of neutron irradiation damage at the nanoscale; particularly across a crystal where it is expected most damage would accumulate at the crystallite boundaries due to the higher diffusion coefficients (compared to bulk volume diffusion). It is therefore proposed that irradiation induced crystallite fragmentation would increase the variability in nanoscale properties.

\section{Acknowledgments}

Funding was provided by the National Nuclear Laboratory and EPSRC (grants EP/J502042/1 and EP/I003312/1). Marzoqa Alnairi would like to acknowledge the Umm AL-QURA University Al-Laith branch, Saudi Arabia, for her PhD scholarship. Helen Freeman would like to acknowledge the Helmholtz Recruiting Initiation funding for Liane G. Benning. Fred Hage provided significant support with the EELS fitting technique and would like to acknowledge Magnus Kristofer Nord (Norwegian University of Science and Technology, Trondheim, Norway) for assistance and useful discussions when setting up the C-K edge fitting procedure in HyperSpy (freely available from http://hyperspy.org/). Jean-Pierre Da Costa and the late Patrick Weisbecker provided us access to the PyroMaN image analysis software and acknowledge support from the ANR agency through a grant to the program "PyroMaN" (ANR-BLAN2010-0929).

\section{References}

[1] R.E. Nightingale, Nuclear Graphite, Academic Press, 1962.

[2] K. Wen, J. Marrow, B. Marsden, Microcracks in nuclear graphite and highly oriented pyrolytic graphite (HOPG), J. Nucl. Mater 381 (2008) 199-203, http:// dx.doi.org/10.1016/j.jnucmat.2008.07.012.

[3] H.M. Freeman, A.N. Jones, M.B. Ward, F.S. Hage, N. Tzelepi, Q.M. Ramasse, A.J. Scott, R.M.D. Brydson, On the nature of cracks and voids in nuclear graphite, Carbon N. Y. 103 (2016) 45-55. http://dx.doi.org/10.1016/j.carbon. 2016.03.011.

[4] C. Berre, S.L. Fok, B.J. Marsden, L. Babout, a. Hodgkins, T.J. Marrow, P.M. Mummery, Numerical modelling of the effects of porosity changes on the mechanical properties of nuclear graphite, J. Nucl. Mater 352 (2006) 1-5, http://dx.doi.org/10.1016/j.jnucmat.2006.02.037.

[5] H. Matsuo, The effect of porosity on the thermal conductivity of nuclear graphite, J. Nucl. Mater 89 (1980) 9-12, http://dx.doi.org/10.1016/00223115(80)90003-3.

[6] B. Hagos, A.N. Jones, T.J. Marrow, B.J. Marsden, Microstructural Analysis of Irradiated Nuclear Graphite Waste, in: DIAMOND’10 Conf., 2010.

[7] J. Kane, C. Karthik, D.P. Butt, W.E. Windes, R. Ubic, Microstructural characterization and pore structure analysis of nuclear graphite, J. Nucl. Mater 415 (2011) 189-197, http://dx.doi.org/10.1016/j.jnucmat.2011.05.053.

[8] C. Karthik, J. Kane, D.P. Butt, W.E. Windes, R. Ubic, Neutron irradiation induced microstructural changes in NBG-18 and IG-110 nuclear graphites, Carbon N. Y. 86 (2015) 124-131, http://dx.doi.org/10.1016/j.carbon.2015.01.036.

[9] N.C. Gallego, R.A. Meisner, T.D. Burchell, Annealing studies of irradiated HOPG using X-ray measurements, in: Int. Nucl. Graph. Spec. Meet, IAEA Knowledge Base on Nuclear Graphite, Seattle, 2013. web.ornl.gov/sci/physical_sciences_ directorate/mst/.../pdf/paper36_Gallego.pptx.

[10] Z. Zhou, W.G. Bouwman, H. Schut, C. Pappas, Interpretation of X-ray diffraction patterns of (nuclear) graphite, Carbon N. Y. 69 (2014) 17-24, http:// dx.doi.org/10.1016/j.carbon.2013.11.032.

[11] B. Kwiecinska, I. Suárez-Ruiz, C. Paluszkiewicz, S. Rodriques, Raman spectroscopy of selected carbonaceous samples, Int. J. Coal Geol. 84 (2010) 206-212, http://dx.doi.org/10.1016/j.coal.2010.08.010.

[12] K. Niwase, T. Tanabe, Defect structure and amorphization of graphite irradiated by D+ and He+, Mater. Trans. JIM 34 (1993) 1111-1121.

[13] R.H. Telling, M.I. Heggie, Radiation defects in graphite, Philos. Mag. 87 (2007) 4797-4846, http://dx.doi.org/10.1080/14786430701210023.

[14] B.T. Kelly, A simple model of the effect of interstitial atoms on the interlayer properties of a graphite crystal, Carbon N. Y. 9 (1971) 627-631.

[15] F. Banhart, Irradiation effects in carbon nanostructures, Rep. Prog. Phys. 62 (1999) 1181-1221. S0034-4885(99)97991-5.

[16] G. Hall, B.J. Marsden, S.L. Fok, The microstructural modelling of nuclear grade graphite, J. Nucl. Mater 353 (2006) 12-18, http://dx.doi.org/10.1016/ j.jnucmat.2006.02.082.

[17] B.E. Mironov, H.M. Freeman, A.P. Brown, F.S. Hage, A.J. Scott, A.V.K. Westwood J.-P. Da Costa, P. Weisbecker, R.M.D. Brydson, Electron irradiation of nuclear graphite studied by transmission electron microscopy and electron energy loss spectroscopy, Carbon N. Y. 83 (2015) 106-117, http://dx.doi.org/10.1016/ j.carbon.2014.11.019. 
[18] C. Karthik, J. Kane, D.P. Butt, W.E. Windes, R. Ubic, In situ transmission electron microscopy of electron-beam induced damage process in nuclear grade graphite, J. Nucl. Mater 412 (2011) 321-326, http://dx.doi.org/10.1016/ j.jnucmat.2011.03.024.

[19] M. Takeuchi, S. Muto, T. Tanabe, H. Kurata, K. Hojou, Structural change in graphite under electron irradiation at low temperatures, J. Nucl. Mater 271-272 (1999) 280-284, http://dx.doi.org/10.1016/S0022-3115(98)007144.

[20] K.N. Kushita, K. Hojou, In situ EELS observation of graphite structure modification due to hydrogen ion irradiation, Ultramicroscopy 35 (1991) 289-293, http://dx.doi.org/10.1016/0304-3991(91)90081-g.

[21] A.P. Burden, J.L. Hutchison, Real-time observation of fullerene generation in a modified electron microscope, J. Cryst. Growth 158 (1996) 185-188, http:// dx.doi.org/10.1016/0022-0248(95)00547-1.

[22] W. Windes, Data Report on Post-irradiation Dimensional Change in AGC-1 Samples, Idaho Natl. Labs, 2012. http://www.inl.gov/technicalpublications documents/5516348.pdf.

[23] W. Swank, AGC-1 Post-irradiation Examination Status, Idaho Natl. Labs, 2011.

[24] W.E. Windes, W.D. Swank, D.T. Rohrbaugh, J.R. Lord, AGC-2 Graphite Preirradiation Data Analysis Report, Idaho Natl. Labs, 2013. http://www.inl.gov/ technicalpublications/Documents/5723145.pdf.

[25] S. Ishiyama, T.D. Burchell, M. Eto, The effect of high fluence neutron irradiation on the properties of a fine-grained isotropic nuclear graphite, J. Nucl. Mater 230 (1996) 1-7, http://dx.doi.org/10.1016/0022-3115(96)00005-0.

[26] G. Williamson, W. Hall, X-ray line broadening from filed aluminium and wolfram, Acta Metall. 1 (1953) 22-31, http://dx.doi.org/10.1016/00016160(53)90006-6.

[27] P. Mallet-Ladeira, P. Puech, P. Weisbecker, G.L. Vignoles, Behavior of Raman D band for pyrocarbons with crystallite size in the $2-5 \mathrm{~nm}$ range, Appl. Phys. A (2014) 759-763, http://dx.doi.org/10.1007/s00339-013-7671-x.

[28] A.C. Ferrari, J. Robertson, Resonant Raman spectroscopy of disordered, amorphous, and diamond-like carbon, Phys. Rev. B 64 (2001) 1-13, http://
dx.doi.org/10.1103/PhysRevB.64.075414.

[29] H. Daniels, A. Brown, A. Scott, T. Nichells, B. Rand, R. Brydson, Experimental and theoretical evidence for the magic angle in transmission electron energy loss spectroscopy, Ultramicroscopy 96 (2003) 523-534, http://dx.doi.org/ 10.1016/S0304-3991(03)00113-X.

[30] D.B. Williams, C.B. Carter, Transmission Electron Microscopy: a Textbook for Materials Science, second ed., Springer, 2009.

[31] J.P. DaCosta, P. Weisbecker, B. Farbos, J.-M. Leyssale, G.L. Vignoles, C. Germain, Investigating carbon materials nanostructure using image orientation statistics, Carbon N. Y. 84 (2015) 160-173, http://dx.doi.org/10.1016/ j.carbon.2014.11.048.

[32] B.J. Marsden, G.N. Hall, O. Wouters, J.A. Vreeling, J. van der Laan, Dimensional and material property changes to irradiated Gilsocarbon graphite irradiated between 650 and $750^{\circ} \mathrm{C}$, J. Nucl. Mater 381 (2008) 62-67, http://dx.doi.org/ 10.1016/j.jnucmat.2008.07.018.

[33] J.A. Vreeling, O. Wouters, J.G. van der Laan, Graphite irradiation testing for HTR technology at the high flux reactor in Petten, J. Nucl. Mater 381 (2008) 68-75, http://dx.doi.org/10.1016/j.jnucmat.2008.07.041.

[34] A.C. Ferrari, J. Robertson, Interpretation of Raman spectra of disordered and amorphous carbon, Phys. Rev. B 61 (2000) 14095-14107, http://dx.doi.org/ 10.1103/PhysRevB.61.14095.

[35] S. Muto, T. Tanabe, Fragmentation of graphite crystals by electron irradiation at elevated temperatures, J. Electron Microsc. (Tokyo) 48 (1999) 519-523.

[36] S. Muto, T. Tanabe, Damage process in electron-irradiated graphite studied by transmission electron microscopy. I. High-resolution observation of highly graphitized carbon fibre, Philos. Mag. A 76 (1997) 679-690, http://dx.doi.org/ 10.1080/01418619708214029.

[37] H. Daniels, R. Brydson, B. Rand, A. Brown, Investigating carbonization and graphitization using electron energy loss spectroscopy (EELS) in the transmission electron microscope (TEM), Philos. Mag. 87 (2007) 4073-4092, http://dx.doi.org/10.1080/14786430701394041. 